\title{
Visualize the Research Productivity of the Journal of Pakistan Association of Dermatologists Published from 2019 - 1999
}

Zahida Anjum*

Lecturer Cum-Librarian, King Saud Bin Abdulaziz University for Health Sciences, College of Medicine Riyadh, Kingdom of Saudi Arabia

DOI: $\underline{10.36347 / \text { sjams.2020.v08i08.021 }}$

| Received: 18.08.2020 | Accepted: 25.08.2020 | Published: 28.08.2020

*Corresponding author: Zahida Anjum

Abstract

Original Research Article

Introduction of Study: This study is a retrospective portrait of publications, published in the Journal of Pakistan Association of Dermatologists (JPAD) indexed in the Scopus-Elsevier database from 2019 - 1999. Methodology: MS Office Excel Sheet 2010 chose to tabulate the retrieved bibliometric data. Frequency of publications, the number of acquired citations, authors' collaboration, and contribution of institutes functioning in an an-other country aimed to investigate. Results: Total 1368 manuscripts published in seven categories by the journal during the studied period. Original articles $1092 ; 80 \%$, followed by $122 ; 9 \%$ review articles and $80 ; 6 \%$ editorials got the top slot in the production. The published material was generated by $4404 ; 3.2 \%$ authors, majority $1132 ; 82.7$, research papers were written collaboratively, and single or solo authors coined 236; $17.2 \%$ of the articles. Twenty-eight countries contributed in 1368 documents, with 720; 55.3\% documents researchers affiliated to Pakistan, trailed by India 377; 29\%, and Iran 58; 4.4\% on top three slots. Conclusion: The journal of Pakistan Association of Dermatologists (JPAD) consistently publish to promote the writings in the specialty and sub-senilities of clinical dermatology, with a provision of the full range of access and discoverability of ideas and their recognition, awareness with reusability, expert peer-review services through technology.

Keywords: Bibliometric, skin diseases, healthcare, and dermatitis.

Copyright @ 2020: This is an open-access article distributed under the terms of the Creative Commons Attribution license which permits unrestricted use, distribution, and reproduction in any medium for non-commercial use (NonCommercial, or CC-BY-NC) provided the original author and source are credited.

\section{INTRODUCTION AND LITERATURE REVIEW}

A study involves diagnoses of the signs and symptoms of diseases concerns to skin, hair, nails, fat, and management of different therapies in prevention and cure called dermatology [1]. In research, it is common to use bibliometric analysis to assess the output of an active academic correlated number of journals in the same field through the Journal Citation Report (JCR). Via this pattern, a detailed study conducted in 2001 to explore the impact factor of journals' relevance with dermatology and found 0.759 to 0.827 , p a good impact factor as a figure [2]. A fresh study displays the influence of citations in the academic world when an article receives a higher citation, which counts a positive correlation with the educational environment. A cross-sectional study shows that 748 articles published in dermatology journals got 814; $108 \%$ citations published from January to June 2013 [3].
A very different study finds 99 publications in journals indexed in the PubMed database from 1999 2019, which were relevant to dermato-pathology and the constructive role of social media for supporting the communications between patients and medics [4]. Sonia, B analysis the published literature on scabies a sub-specialty of dermatology on the same PubMed database from 2001 - 2015, she found 1460 records; it also reveals that multiple authors collaboratively wrote $86.7 \%$ articles [5]. A bibliometric study determines the contribution of research of countries in any specific discipline or its sub-specialties of the same subjects. Poskevicius, Lukas et al., explore the data of authors or researchers from Baltic countries, wrote scientific publications on the dentistry published from 1996 2018 indexed in best databases; Web of Science and Scopus-Elsevier. 651 papers were published during these 22 years, Lithuania got top slot with 280 publications [6]. 
Clinical dermatology got attention by bibliometric researchers working in the Spanish center of dermatology in 2019; they explore 8617 papers published in Embase and PubMed databases. Survey form sends to them to know the factors supporting time management and distribution of workload in research productivity [7]. Writing articles has always been difficult for researchers to explore and choose the best information to deal with the idea that supports and tackles the challenges and provides results to healthcare providers in eradicating ill health of society [8]. Motivating research on the growth of publications in dermatology and its sub-specialties; infectious disorders, hypopigmentation disorders, neoplastic disorders, hair disorders, and genodermatosis of dermatology conducted by researchers affiliated with King Saud University, Riyadh Saudi Arabia sub-fields of dermatology from 1982-2018, published in reputed journals indexed in PubMed [9]. The online Journal of Pakistan Association of Dermatologists (JPAD) is published quarterly, indexed in Scopus-Elsevier database and ten other highest-ranking databases to serve the local community of researchers associate with the dermatology discipline started in 1992 [10].

\section{Material \& Methods}

Scopus-Elsevier Database is best for downloading the bibliometric data of world-known academic journals; the data of the Journal of Pakistan Association of Dermatologists for the period 20191999 for this study downloaded on 20th of June 2020. Comma-isolated worth (CSV) and Plain text on Notepaid utilized, composed "1560-9014", an International Standard Serial Number (ISSN) was helpful as the source. MS Office Excel Sheet 2010 used for tabularization. Five objectives were set to examine, a) to analysis year-wise publications with occurred citations year-wise, b) to recognize the manuscript type, c) to estimate the author's contribution in publications, d) to check pattern of authorship, e) to figure-out the associations of countries in publications.

\section{RESULTS}

Figure-1 and Table-1 show that the Journal of Pakistan Association of Dermatologists frequently published research manuscripts for twenty-one years, total $1368 ; 65.1 \%$ were published in $84 ; 16.2 \%$ per issue in 21 years. Total 536; 39.1\% articles get citations through-out the date $20^{\text {th }}$ June 2020 . Majority of 100 articles published in the year 2013 and get $44 \%$ of quotes. The year 2008, published 52 articles and got 33; 63.4 citations, followed by $62 \%$ of citations in the year 2006 out of 50 research papers as maximum.

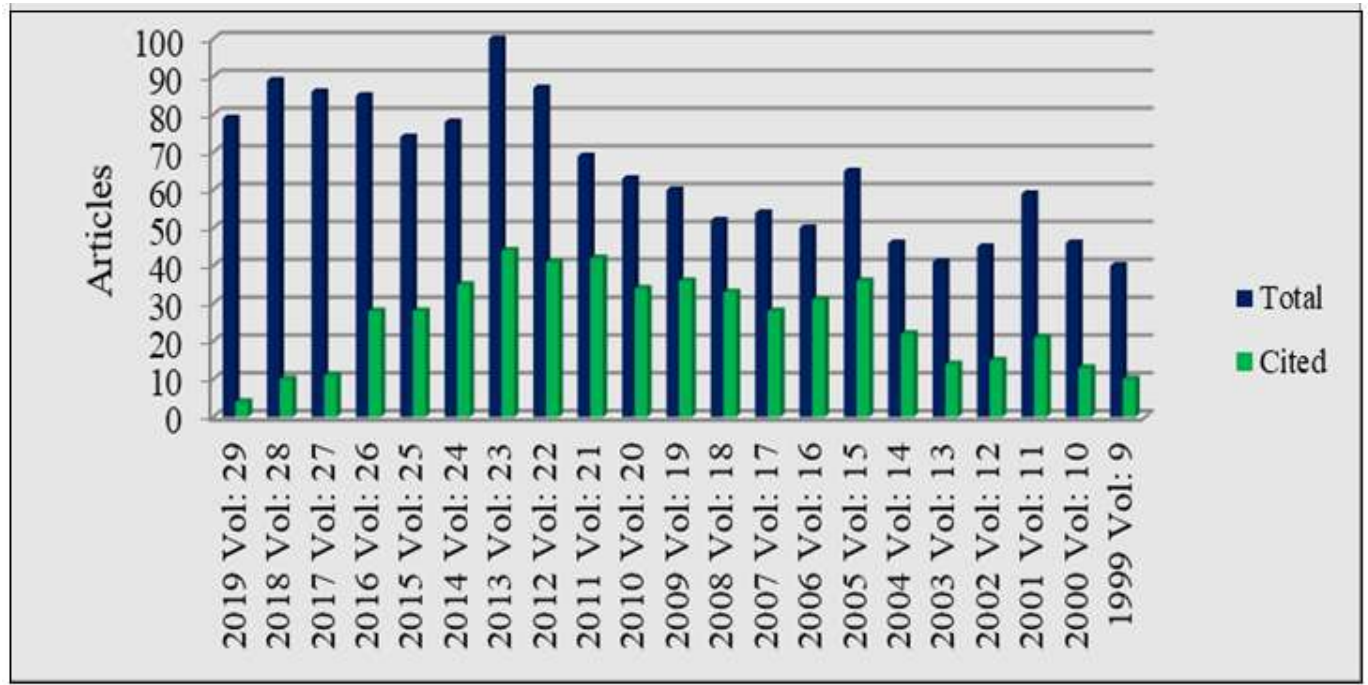

Fig-1: Research productivity of Journal of Pakistan Association of Dermatologists with citations from 2019-1999 
Table-1: Research productivity published in the Journal of Pakistan Association of Dermatologists for the period 2019-1999 with citations got on $20^{\text {th }}$ June 2020 [11]

\begin{tabular}{|c|c|c|c|c|c|c|c|c|c|}
\hline $\begin{array}{l}\text { S. } \\
\text { No }\end{array}$ & Years & $\begin{array}{l}\text { Issue } \\
1\end{array}$ & $\begin{array}{l}\text { Issue } \\
2 \\
\end{array}$ & $\begin{array}{l}\text { Issue } \\
3\end{array}$ & $\begin{array}{l}\text { Issue } \\
4 \\
\end{array}$ & $\begin{array}{l}\text { Total } \\
\text { articles }\end{array}$ & $\begin{array}{l}\text { Cited } \\
\text { articles }\end{array}$ & $\begin{array}{l}\text { Self } \\
\text { cited }\end{array}$ & $\begin{array}{l}\text { Manually } \\
\text { Citation count }\end{array}$ \\
\hline 1 & $2019 \mathrm{~V}: 29$ & 27 & 21 & 15 & 16 & 79 & 4 & 4 & $5 \%$ \\
\hline 2 & $2018 \mathrm{~V}: 28$ & 23 & 28 & 25 & 13 & 89 & 10 & 5 & $11.2 \%$ \\
\hline 3 & $2017 \mathrm{~V}: 27$ & 21 & 21 & 21 & 23 & 86 & 11 & 5 & $12.7 \%$ \\
\hline 4 & $2016 \mathrm{~V}: 26$ & 19 & 19 & 25 & 22 & 85 & 28 & 6 & $33 \%$ \\
\hline 5 & $2015 \mathrm{~V}: 25$ & 18 & 17 & 20 & 19 & 74 & 28 & 4 & $37.8 \%$ \\
\hline 6 & $2014 \mathrm{~V}: 24$ & 22 & 19 & 18 & 19 & 78 & 35 & 2 & $44.8 \%$ \\
\hline 7 & $2013 \mathrm{~V}: 23$ & 25 & 29 & 24 & 22 & 100 & 44 & 2 & $44 \%$ \\
\hline 8 & $2012 \mathrm{~V}: 22$ & 18 & 22 & 25 & 22 & 87 & 41 & 5 & $47.1 \%$ \\
\hline 9 & $2011 \mathrm{~V}: 21$ & 15 & 18 & 17 & 19 & 69 & 42 & 8 & $60.8 \%$ \\
\hline 10 & $2010 \mathrm{~V}: 20$ & 15 & 16 & 18 & 14 & 63 & 34 & 3 & $54 \%$ \\
\hline 11 & $2009 \mathrm{~V}: 19$ & 16 & 14 & 15 & 15 & 60 & 36 & 4 & $60 \%$ \\
\hline 12 & $2008 \mathrm{~V}: 18$ & 13 & 13 & 14 & 12 & 52 & 33 & 2 & $63.4 \%$ \\
\hline 13 & $2007 \mathrm{~V}: 17$ & 16 & 13 & 13 & 12 & 54 & 28 & 2 & $51.8 \%$ \\
\hline 14 & $2006 \mathrm{~V}: 16$ & 13 & 12 & 13 & 12 & 50 & 31 & 11 & $62 \%$ \\
\hline 15 & $2005 \mathrm{~V}: 15$ & 17 & 20 & 15 & 13 & 65 & 36 & 11 & $55.3 \%$ \\
\hline 16 & $2004 \mathrm{~V}: 14$ & 8 & 9 & 11 & 18 & 46 & 22 & 6 & $47.8 \%$ \\
\hline 17 & $2003 \mathrm{~V}: 13$ & 10 & 10 & 11 & 10 & 41 & 14 & 12 & $34.1 \%$ \\
\hline 18 & $2002 \mathrm{~V}: 12$ & 12 & 11 & 11 & 11 & 45 & 15 & 0 & $33.3 \%$ \\
\hline 19 & $2001 \mathrm{~V}: 11$ & 17 & 16 & 15 & 11 & 59 & 21 & 0 & $35.5 \%$ \\
\hline 20 & $2000 \mathrm{~V}: 10$ & 11 & 10 & 11 & 14 & 46 & 13 & 0 & $28.2 \%$ \\
\hline 21 & $1999 \mathrm{~V}: 9$ & 12 & 8 & 6 & 14 & 40 & 10 & 0 & $25 \%$ \\
\hline \multicolumn{2}{|c|}{ Total } & 348 & 346 & 343 & 331 & 1368 & 536 & 97 & \\
\hline \multicolumn{2}{|c|}{ Percentage } & $25.4 \%$ & $25.2 \%$ & $25 \%$ & $24.2 \%$ & 65.1 per year & $\begin{array}{l}15.5 \\
\text { per issue }\end{array}$ & $18 \%$ & $39.1 \%$ \\
\hline
\end{tabular}

Figure-2 indicates the clear picture of publications, published in the Journal of Pakistan Association of Dermatologists from 2019-1999. Original 1092 followed by 122 review articles and 80 editorials got the top slot in the production out of a note, short survey, erratum, and letters out of 1368 documents.

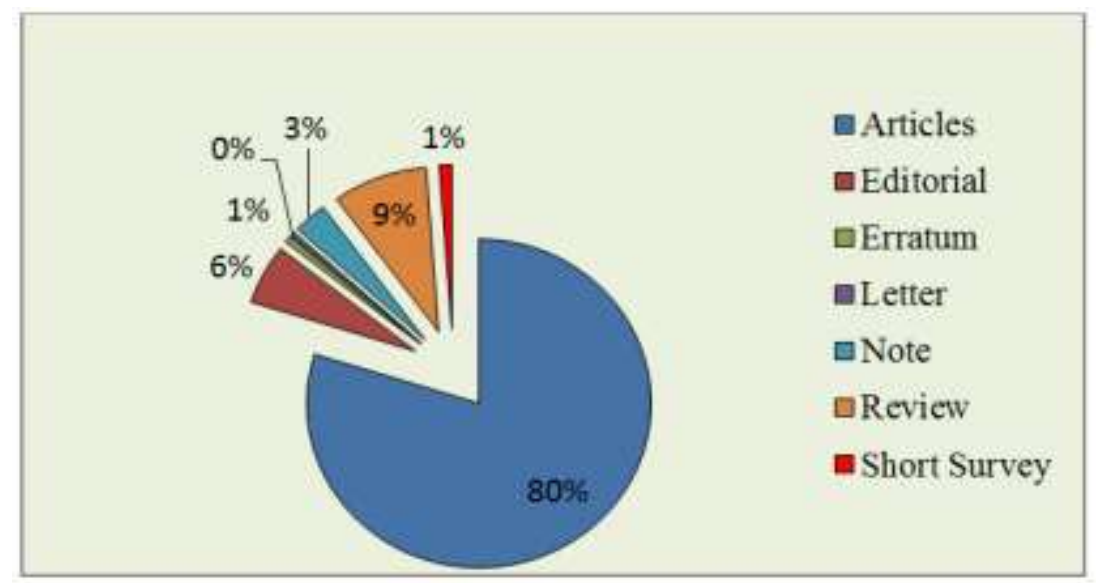

Fig-2: Types of documents published in Journal of Pakistan Association of Dermatologists from 2019-1999

Collaborative writing is familiar in this era among experts in areas of their discipline, and information technology tools support to scientists to fulfill the objectives of their interdisciplinary research for progressing in pure science into applied sciences $[12]$.

Figure-3, and Table-2, show the fascinating combination of authors involved in producing research and published from 1999-2019. Total 4404; 3.2\% of authors presented 1368 documents in the 88 issues of the Journal of Pakistan Association of Dermatologists 2019-1999. The breakdown of authorship-pattern reveals that the majority $1132 ; 82.7$ articles written in collective manners, only $236 ; 17.2 \%$ articles written by single or solo authors.

For more understanding, authorship pattern multiple with the number of articles written by researchers, i.e. $(267 \times 2=534) 267$ articles written by two authors and the 534 is the number of total authors. 


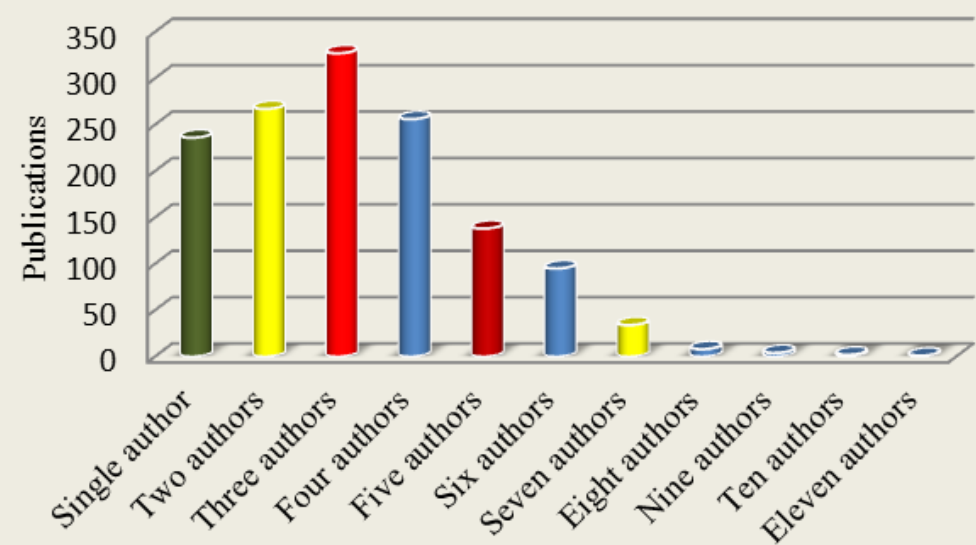

Fig-3: Authorship-pattren in research productivity of Journal of Pakistan Association of Dermatologists from 2019-1999

Table-2: Pattern of authorship in research productivity of the Journal of Pakistan Association of Dermatologists from $2019-1999$

\begin{tabular}{|c|c|c|c|c|c|c|c|c|c|c|c|c|c|c|c|c|c|c|c|c|c|c|c|c|c|}
\hline & & & & & & & & & & & & & & & & & & & & & & & & & \\
\hline $\begin{array}{l}\stackrel{0}{Z} \\
\dot{\Omega}\end{array}$ & 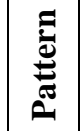 & 홍 & $\stackrel{\infty}{\bar{d}}$ & 공 & 光 & $\frac{n}{8}$ & ষ্ণ & $\stackrel{m}{\bar{\tau}}$ & 공 & $\overline{\bar{\nu}}$ & 록 & હે & $\stackrel{\infty}{\stackrel{\overbrace{}}{్}}$ & 용 & ஓ્ఠ & ஜ̊ & ষ্ণ & $\stackrel{\overbrace{}}{\tilde{\Xi}}$ & ్ㅀㅇ & ఠ్రి & శ్రి & बे & 节 & $0^{\circ}$ & 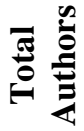 \\
\hline- & 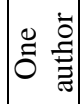 & 0 & $a$ & $n$ & $\infty$ & 0 & $r$ & 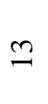 & 으 & $\varrho$ & $r$ & 0 & $n$ & $\nabla$ & 으 & I & $\simeq$ & $a$ & $\stackrel{\infty}{\sim}$ & iv & 고 & $\stackrel{\sim}{\sim}$ & तి & 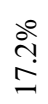 & లి \\
\hline$N$ & 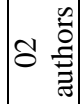 & - & $\simeq$ & 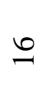 & $\simeq$ & $\underline{0}$ & $\cong$ & $\stackrel{2}{2}$ & $\underline{2}$ & $\simeq$ & \pm & I & $\cong$ & $\bar{\sim}$ & $\stackrel{ }{ }$ & $=$ & 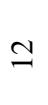 & $a$ & 0 & $\varrho$ & 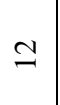 & $\infty$ & î. & $\begin{array}{l}\text { b̊ } \\
\text { å } \\
\end{array}$ & $\stackrel{ \pm}{n}$ \\
\hline$m$ & 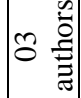 & $=$ & $\bar{\lambda}$ & $\mathscr{\imath}$ & $\hat{\imath}$ & 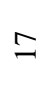 & $\bar{\sim}$ & $\stackrel{\infty}{\sim}$ & $\stackrel{0}{-}$ & $\simeq$ & \pm & $\stackrel{\infty}{\simeq}$ & $\underline{=}$ & \pm & $\underline{0}$ & $\bar{\sim}$ & 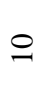 & $\stackrel{\infty}{\sim}$ & 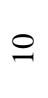 & 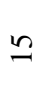 & $=$ & $\sim$ & & $\stackrel{\stackrel{\circ}{+}}{\sim}$ & ळ \\
\hline$\nabla$ & 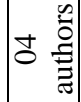 & $\because$ & I & $\widetilde{\sim}$ & $\cong$ & 고 & I & $\cong$ & $\stackrel{\Delta}{\sim}$ & $=$ & 2 & $\simeq$ & $a$ & in & $\infty$ & 0 & $\stackrel{\varrho}{0}$ & $\nabla$ & $a$ & $n$ & $m$ & $m$ & $\stackrel{\check{n}}{\sim}$ & $\begin{array}{l}\frac{\partial}{2} \\
\infty \\
\infty\end{array}$ & 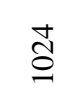 \\
\hline$n$ & $\begin{array}{ll}n & 0 \\
0 & \vdots \\
\Xi\end{array}$ & \pm & I & $\underline{\sim}$ & $\infty$ & $\varrho$ & $\infty$ & $\underline{\sigma}$ & 으 & $a$ & $\nabla$ & $n$ & $\nabla$ & $\forall$ & $\nabla$ & $m$ & $\sim$ & - & - & $\sim$ & & $\sim$ & $\stackrel{\infty}{\sim}$ & 80 & 8 \\
\hline 6 & $\begin{array}{ll}8 & \vdots \\
\end{array}$ & $a$ & $\stackrel{0}{=}$ & $\infty$ & $\infty$ & $\nabla$ & in & $\Xi$ & $a$ & $a$ & $m$ & $\forall$ & $\nabla$ & $m$ & - & 6 & & & & & & - & $n$ & $\frac{b}{r}$ & $\stackrel{?}{i}$ \\
\hline$r$ & $\begin{array}{ll}1 & \vdots \\
0 & \vdots \\
\vdots\end{array}$ & $\nabla$ & $m$ & $N$ & $n$ & & $\nabla$ & $N$ & $\nabla$ & 0 & $N$ & & - & $N$ & - & & & & & & & & mे & 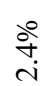 & $\stackrel{\infty}{\sim}$ \\
\hline$\infty$ & 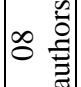 & - & & - & & & & - & - & & & & - & & & - & & & - & - & & & $\infty$ & $\begin{array}{l}0 \\
n \\
0\end{array}$ & t \\
\hline$a$ & 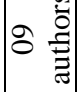 & - & & & - & - & - & & & & & & & & & & & & & & & & $\nabla$ & $\stackrel{\stackrel{\circ}{0}}{0}$ & ల్ల \\
\hline
\end{tabular}




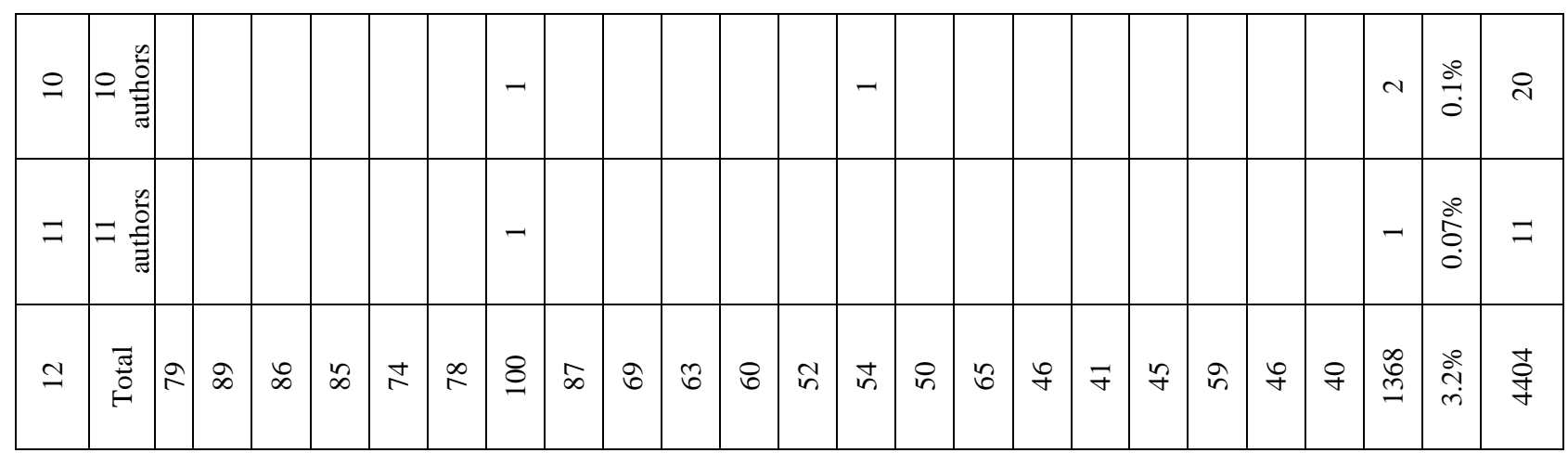

Figure-4 and Table-3 show that 28 countries participated in 1302 documents, some-times some authors affiliated with one institute and some researchers associated with different institutes. Majority documents scripted by Pakistan, followed by India, Iran, Bangladesh, Saudi Arabia, and the United States, as in the top seven countries. Nepal and Turkey present
06 articles, Kuwait 04 articles, Sierra Leone, and Syria with 03 reports, United Kingdome, Bulgaria, Japan, Qatar, and Slovakia contributed with 02 articles. Eleven countries; Australia, Bahrain, China, Croatia, Libya, Malaysia, Oman, Spain, Sri Lanka, Serbia, and United Arab Emirates added one article each.

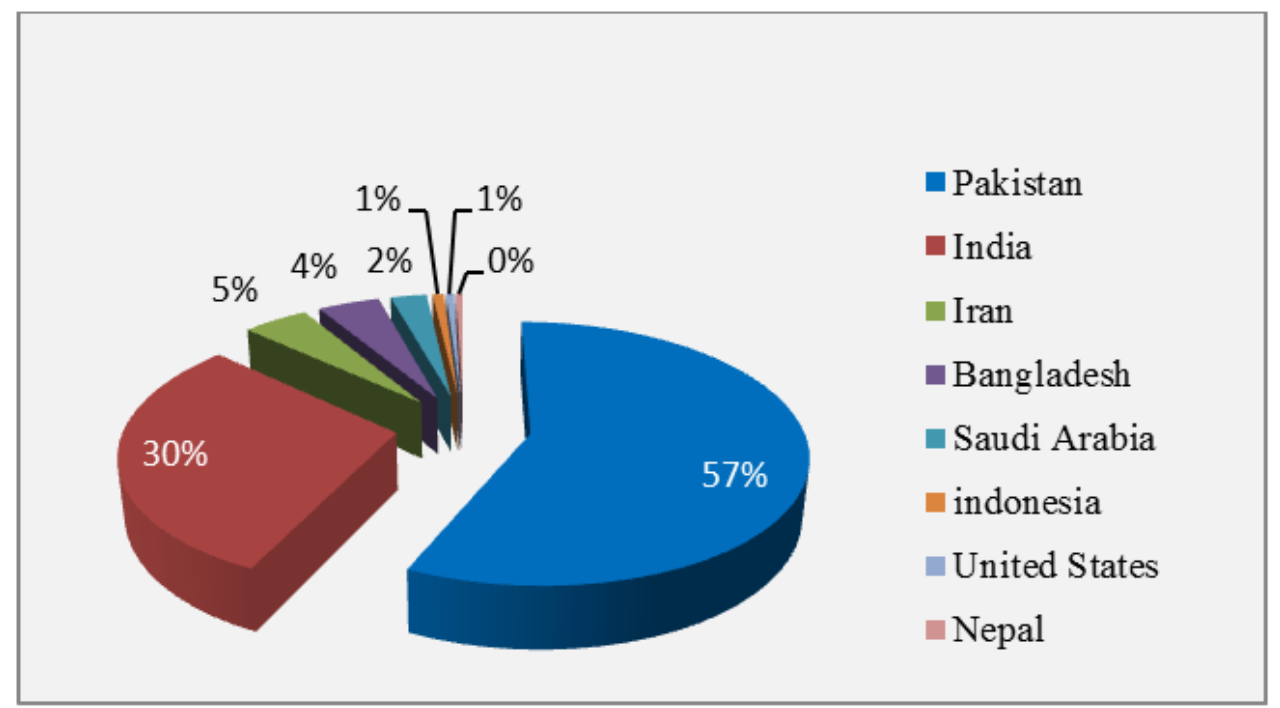

Fig-4: Participation of top eight countries in research productivity of Journal of Pakistan Association of Dermatologists from 2019-1999

Table-3: Participation of top eight countries in research productivity of Journal of Pakistan Association of Dermatologists from 2019-1999

\begin{tabular}{|l|l|l|}
\hline S. No & Country & Publications with \% \\
\hline 1 & Pakistan & $720(55.3 \%)$ \\
\hline 2 & India & $377(29 \%)$ \\
\hline 3 & Iran & $58(4.4 \%)$ \\
\hline 4 & Bangladesh & $55(4.2 \%)$ \\
\hline 5 & Saudi Arabia & $32(2.4 \%)$ \\
\hline 6 & Indonesia & $10(0.7 \%)$ \\
\hline 7 & United States & $7(0.5 \%)$ \\
\hline 8 & 02 Countries participate with 06 articles & $6(0.4 \%)$ \\
\hline 9 & 01 Country participate with 04 articles & $4(0.3 \%)$ \\
\hline 10 & 02 Countries participate with 03 articles & $3(0.2 \%)$ \\
\hline 11 & 05 Countries participate with 02 articles & $2(0.1 \%)$ \\
\hline 12 & 11 Countries participate with 01 article & $1(0.08 \%)$ \\
\hline 13 & Total participation & 1302 \\
\hline
\end{tabular}




\section{DisCUSSION \& CONCLUSION}

The research pertained to conceptual findings, visibility, theoretical approaches, and the critical role of researchers in contributing to clear conclusions and this lead to publishing highest-ranked journals and cited in providing help to get academic success. 11The Journal of Pakistan Association of Dermatologists (JPAD) is an open-access journal regularly published under the umbrella of association. It acquires the attention of academic community relevance to the active discussion and problem-solving strategies of researchers. 12 The editorial policy of the journal ascent the writers profile and welcomed in the network of thinker's landscapes.

Disclaimer: None to declare.

Conflict of Interest: None to declare.

Funding Disclosure: None to declare.

\section{REFERENCES}

1. Jemec GB, Nybæk H. A bibliometric study of dermatology in central Europe 1991-2002. International journal of dermatology. 2006 Aug;45(8):922-6.

2. Jemec GB. Impact factors of dermatological journals for 1991-2000. BMC dermatology. 2001 Dec 1;1(1):7.

3. Kim HS, Wahid M, Choi C, Das P, Jung S, Khosa F. Bibliometric Analysis of Manuscript Characteristics that Influence Citations: A Comparison of Ten Major Dermatology Journals. Burns. 2020 May 16.

4. Saleh J, Dahiya M. Social media trends in dermatology, dermatopathology, and pathology publications: The social construction of medical subdisciplines. Journal of Cutaneous Pathology. 2020 Mar 11.

5. Bansal S. A Bibliometric Study of World Research Publications on Scabies. Library Waves-A
Biannual Peer Reviewed Journal. 2019 Jun 30;5(1):29-34.

6. Poskevicius L, De la Flor-Martínez M, GalindoMoreno P, Juodzbalys G. Scientific publications in dentistry in Lithuania, Latvia, and Estonia between 1996 and 2018: A bibliometric analysis. Medical science monitor: international medical journal of experimental and clinical research. 2019;25:4414.

7. Molina-Leyva A, Descalzo MA, García-Doval I. Clinical research in Dermatology: resources and activities associated with a higher scientific productivity. Giornale italiano di dermatologia e venereologia: organo ufficiale, Societa italiana di dermatologia e sifilografia. 2018 Mar 6;154(4):386-91.

8. Beecroft C, Booth A, Otter ME, Keen C, Lynch C. Supporting 'Best Research for Best Health'with best information. Health Information \& Libraries Journal. 2009 Dec;26(4):307-15.

9. Alsaif FM, Alsukait SF, Alsaad AB, Alfurayh NA, Alhallaf RA, Alhaddab SA, Alotaibi HM. Publications pattern of dermatology research in Saudi Arabia. Saudi Medical Journal. 2020 May 1;41(5):524-31.

10. Ijaz H. Journal of Pakistan Association of Dermatologists. 2020. Available to download at: http://pad.org.pk/.

11. Scimag shows self-citation report published and retrieved from below: https://www.scimagojr.com/journalsearch.php?q=1 $2978 \&$ tip $=$ sid \&clean $=0$.

12. Arya C, Sharma S. Authorship trends and collaborative research in veterinary sciences: A bibliometric study. Chinese Librarianship: an International Electronic Journal. 2011;34:1-9.

13. Lindgreen A, Di Benedetto CA, Brodie RJ, Fehrer J, Van der Borgh M. How to get great research cited. Industrial Marketing management. 2020.

14. Pourret O, Hursthouse A, Irawan DE, Johannesson K, Liu H, Poujol M, Tartese R, van Hullebusch ED, Wiche O. Open Access publishing practice in geochemistry: overview of current state and look to the future. Heliyon. 2020 Mar 1;6(3):e03551. 